\title{
RESEARCH
}

\section{ATTITUDES OF FAMILY PHYSICIANS TOWARDS THE ELDERLY}

Turkish Journal of Geriatrics

DOI: 10.31086/tigeri.2020.162

2020; 23(2): 270-277

- Hüseyin ELBi ${ }^{1}$ (D)

- Fatih ÖZCAN ${ }^{1}$ (D)

- Beyhan CENGIZ ÖZYURT² (D)

- Muhteşem Erol YAYLA ${ }^{3}$ D

CORRESPONDANCE

Hüseyin ELBI

Manisa Celal Bayar University, Faculty of Medicine, Department of Family Medicine, Manisa, TURKEY.

Phone: +905055569911

e-mail: hsynelbi1@hotmail.com

Received: April 02, 2020

Accepted: May 14, 2020

1 Manisa Celal Bayar University, Faculty of Medicine, Department of Family Medicine, Manisa, TURKEY

${ }^{2}$ Manisa Celal Bayar University, Faculty of Medicine, Department of Public Health, Manisa, TURKEY

${ }^{3}$ Adana City Training and Research Hospital, Family Medicine Clinic, Adana, TURKEY

\section{Abstract}

Introduction: It is stated that negative attitudes towards the elderly affect the diagnosis and treatment processes negatively. Nevertheless, there are not enough recent studies examining the attitudes of family physicians who provide widespread healthcare to the elderly. The aim of this study was to evaluate the attitudes of family physicians towards the elderly.

Material and Methods: Participants of this descriptive study are family physicians working actively in primary care. Data were collected through the software program, between January and June 2018. The link to the questionnaire was sent to the participants via e-mail. The questionnaire consisted of two parts: the sociodemographic data and University of California at Los Angeles Geriatrics Attitude (UCLA-GA) scale.

Results: A total of 401 family physicians, 216 of whom (53.9\%) were women, participated in the study. The mean age of the participants was $41.19 \pm 8.51$ years. On evaluation of both the mean total score $(42.36 \pm 3.42)$ and mean subscale score $(3.02 \pm 0.24)$, it was observed that female participants scored significantly higher ( $p$ $=0.001)$. Moreover, the UCLA-GA medical care subscale score raised with increased working time at family medicine $(r=0.151, p=0.002)$ or being a medical doctor $(r=$ $0.14, p=0.005)$ and with growing age $(r=0.15, p=0.003)$.

Conclusion: The results of our study showed that those with longer professional experience, being older age, and women are associated with positive attitude towards the elderly. However, intervention studies are required to improve family physicians' attitudes towards the elderly.

Keywords: Aged; Attitude; Family Physician. 


\section{INTRODUCTION}

In the last quarter century, due to a significant reduction in the birth rates and an increase in the life expectancy, a relatively rapid increase in the percentage of elderly population has been witnessed in Turkey, as well as across the world (1). This rapid change has an important effect on the emergence of different requests, both in the application to the health institutions and the services provided there (2). Although the demographic change in the countries is rapid, unfortunately, developments in both sociological and elderly health are not at the same pace (3). The conditions such as chronic health problems, requirement of more complex treatments, multiple drug usage, etc. in the elderly population, directly affect the healthcare services provided by health workers to the elderly (4).

It is important to recognize the attitudes of physicians, the important stakeholders of healthcare and the first contacts in primary care, towards aging and old age, since age-related discriminatory attitudes may adversely affect the quality of healthcare received by the elderly (5). Moreover, negative attitudes towards the elderly in the field of healthcare have exerted negative effects on the diagnosis and treatment processes (6).

Although aging and old age have become more recognized phenomena among doctors, many studies show that health professionals, including doctors, have a negative attitude towards the elderly $(7,8)$. This situation is more clearly observed especially towards the oldest ages and dependent elderly (9). It was shown that $16 \%$ of general practitioners in some cases decided not to refer older patients for further treatment because they suspected that the patients will not be treated due to their age (10).

Some recent studies demonstrate more mixed attitudes of the healthcare professionals towards the older people $(8,9,11)$. Although, in 1985 , the elderly were thought to be uninterested, close, conservative and irritable in their beliefs and daily practice by family physicians (12), there were no sufficient studies investigating the factors that may contribute to the evaluation of the general attitude of family physicians towards the elderly. The aim of this study was to: (i) investigate attitudes of family physicians towards the elderly and (ii) determine the factors (age, gender, work experience, etc.) that could guide further studies among other health professionals.

\section{MATERIAL AND METHODS}

\section{Selection of participants}

Family medicine system has been piloted in Turkey since 2005. This system was fully implemented in January 2011 throughout the country. The universe of this descriptive study is 24,428 family physicians, actively working in the family medicine system in the country according to 2017 data. Turkey has no general database consisting e-mail addresses of family physicians. The e-mail addresses of approximately 2500 family physicians obtained after extracting duplications from different communication channels were determined as the target audience. A questionnaire was sent to these registered e-mail addresses in a onemonth period, and reminders were sent a total of 2 times after the respondents were removed. At the end of this period, a total of 407 family physicians answered the questionnaire. 6 of them were excluded from the statistical analysis since containing missing data. Analysis was performed on a total of 401 people.

\section{Data collection}

Data were assimilated through the software survey program. The link to the questionnaire was sent to the participants via e-mail. The questions we wanted the participants to answer were mentioned in this questionnaire, and the participants were not allowed to skip any of the questions. The data were collected between January and June 2018. 


\section{Instruments}

The questionnaire consisted of two parts: the sociodemographic data and the University of California at Los Angeles Geriatrics Attitude (UCLA-GA) scale. In the data collection form, socio-demographic characteristics, the region the participants serve in (rural/urban) and information on working time, in both occupational and family medicine system, were recorded.

\section{UCLA Geriatrics Attitude (UCLA-GA) Scale:}

The scale, developed by Reuben, consists of fourteen questions and is used to assess attitudes towards the elderly. The Turkish validity and reliability of the scale was conducted by Şahin in 2011 (13). The UCLA-GA scale has four dimensions: social values, medical care, compassion and resources distribution. The total score is obtained by combining the four dimensions. The highest possible score is 70 and higher scores show a more positive attitude. The average scores of the individual questions can be interpreted as: 1 to 2 indicating negative scores, 3 indicating neutral scores and 4 to 5 indicating positive scores.

\section{Statistical Analysis}

The data obtained from the study were evaluated with the SPSS 15.0 program. In the descriptive statistics, student-t test for the comparison of two independent groups in terms of continuous data when normal distribution conditions were achieved (Mann-Whitney U-test when normal distribution conditions were not met), one-way analysis of variance for comparison of three or more groups in terms of continuous data (KruskalWallis test if normal distribution conditions were not met) and Pearson's correlation test to compare two continuous data were applied.

\section{Compliance with ethical standards \\ Conflict of interest}

The authors declare that they have no conflict of interest.

\section{Ethical approval}

All procedures performed in studies involving human participants were in accordance with the ethical standards of the institutional and/or national research committee (Local University, Faculty of Medicine Ethics Committee of Health Sciences + reference number: 20478486) and with the 1964 Helsinki declaration and its later amendments or comparable ethical standards. All participants expressed their consent by marking it on the consent form, which was electronically illuminated.

\section{Informed consent}

Informed consent was obtained from all individual participants included in the study.

\section{RESULTS}

A total of 401 family physicians, 216 of whom (53.9\%) were women, participated in the study. The mean age of the participants was $41.19 \pm 8.51$ years (min: 26 years, max: 62 years). According to the study area, $68.6 \%$ of the participants were working in urban areas (Table 1).

The mean UCLA-GA total score of the participants was $41.79 \pm 3.69$ (min-max: 30-61) and the mean score for individual questions was $2.98 \pm 2.63$ (min-max: 2.29-3.86). On gender-wise evaluation of the mean total score and mean score of the individual questions, it was observed that female participants scored significantly higher ( $p$ $=0.001)$.

When the social values, medical care, compassion and resource distribution subscale scores of the scale were evaluated, respectively, female participants and the physicians under 40 years of age scored significantly higher in the UCLA-GA social values subscale $(p=0.025)$. As the mean year for the study was 6.5 years in the family medicine, the cut-off year was 6 years for the family medicine and the cut-off year was 15 years for the physician's working period as 16.3 . 
Table 1. General Information about the Participants.

\begin{tabular}{|c|c|}
\hline Features & $N(\%)$ \\
\hline \multicolumn{2}{|l|}{ Gender } \\
\hline Female & $216(53.8)$ \\
\hline Male & 185(46.2) \\
\hline \multicolumn{2}{|l|}{ Age (year) } \\
\hline$<40$ & $172(42.9)$ \\
\hline$\geq 40$ & $229(57.1)$ \\
\hline \multicolumn{2}{|l|}{ Professional year } \\
\hline$<15$ & $190(47.4)$ \\
\hline$\geq 15$ & $211(52.6)$ \\
\hline \multicolumn{2}{|l|}{ Working as a family physician (year) } \\
\hline$<6$ & $160(39.9)$ \\
\hline$\geq 6$ & $258(60.1)$ \\
\hline \multicolumn{2}{|l|}{ Working area } \\
\hline Rural & 85 (21.3) \\
\hline Urban & $275(68.5)$ \\
\hline Slums & $41(10.2)$ \\
\hline Professional year (mean, sd) & $16.31 \pm 8.71$ \\
\hline Working as a family physician (mean, sd) & $6.50 \pm 3.55$ \\
\hline Age (mean, sd) & $41.19 \pm 8.51$ \\
\hline UCLA-GA total score (mean, sd) & $41.79 \pm 3.69$ \\
\hline UCLA-GA mean score (mean, sd) & $2.98 \pm 2.63$ \\
\hline
\end{tabular}

Physicians older than 40 years (total subscale mean score $=13.35, p<0.003$ ), physicians working since a duration of 15 years or more (total subscale mean score $=13.33, p<0.005)$ and those who worked in the family medicine system for more than 6 years (total subscale mean score $=13.33, p<0.002$ ) reported more positive attitudes in medical care subscale (Table 2).

The UCLA-GA medical care subscale score raised with increased working time in family medicine ( $r=0.151, p=0.002)$ or with being a medical doctor $(r=0.14, p=0.005)$ and growing age $(r=0.15, p=0.003)$. There was no significant difference between the attitudes of the family physicians working in urban/rural areas or the percentage of elderly population registered with a family physician.

The only variable affecting the total score of UCLA-GA scale and included in the determinants of UCLA-GA social values sub-scale score was found to be gender $(r 2=0.015)$. In multivariate analysis, there was no determinant variable in the UCLA-GA medical care subscale score in the three-variable model. In the study, it was decided to keep the age variable in the model because autocorrelations were found to be high and meaningful ( $r$ values between 0.063 and $0.097, p<$ 0.0001 ) among the variables of age, occupational year and family physician who explained UCLAGA medical care subscale score. This model is 
Table 2. Comparison of UCLA scores according to sociodemographic characteristics.

\begin{tabular}{|c|c|c|c|c|c|}
\hline & Social values & Medical care & Compassion & $\begin{array}{r}\text { Resources } \\
\text { distribution }\end{array}$ & UCLA-GA Total \\
\hline \multicolumn{6}{|l|}{ Gender } \\
\hline Female & $5.45 \pm 1.60$ & $13.24 \pm 2.27$ & $12.44 \pm 2.37$ & $11.22 \pm 1.80$ & $42.36 \pm 3.42$ \\
\hline Male & $5.07 \pm 1.74$ & $12.78 \pm 2.67$ & $12.34 \pm 2.84$ & $10.92 \pm 2.13$ & $41.14 \pm 3.89$ \\
\hline $\mathrm{p}$ & .025 & .068 & .072 & .098 & .001 \\
\hline \multicolumn{6}{|l|}{ Age (year) } \\
\hline$<40$ & $5.48 \pm 1.59$ & $12.60 \pm 2.57$ & $12.55 \pm 2.63$ & $11.05 \pm 2.06$ & $41.69 \pm 3.81$ \\
\hline$\geq 40$ & $5.12 \pm 1.73$ & $13.35 \pm 2.35$ & $12.28 \pm 2.56$ & $11.10 \pm 1.89$ & $41.87 \pm 3.60$ \\
\hline$p$ & .036 & .003 & .306 & .798 & .638 \\
\hline \multicolumn{6}{|l|}{ Professional year } \\
\hline$<15$ & $5.45 \pm 1.58$ & $12.64 \pm 2.55$ & $12.55 \pm 2.66$ & $11.02 \pm 2.03$ & $41.67 \pm 3.80$ \\
\hline$\geq 15$ & $5.13 \pm 1.74$ & $13.33 \pm 2.36$ & $12.27 \pm 2.54$ & $11.13 \pm 1.91$ & $41.89 \pm 3.60$ \\
\hline $\mathrm{p}$ & .059 & .005 & .290 & .559 & .563 \\
\hline \multicolumn{6}{|c|}{ Working as a family physician (year) } \\
\hline$<6$ & $5.34 \pm 1.67$ & $12.48 \pm 2.48$ & $12.59 \pm 2.64$ & $11.06 \pm 2.04$ & $41.48 \pm 3.90$ \\
\hline$\geq 6$ & $5.24 \pm 1.69$ & $13.33 \pm 2.41$ & $12.29 \pm 2.56$ & $11.09 \pm 1.92$ & $41.96 \pm 3.56$ \\
\hline $\mathrm{p}$ & .575 & .002 & .263 & .896 & .213 \\
\hline
\end{tabular}

Table 3. Multivariate analysis explaining the relationship between UCLA-GA sub-scales and socio-demographic characteristics.

\begin{tabular}{|l|r|r|r|r|}
\hline & R2 & Coefficient (B) & 95\% Cl & P \\
\hline UCLA-GA Social values & .015 & & & \\
\hline Constant & & & 4.627 to 6.349 & .000 \\
\hline Gender & & .106 & .024 to .689 & \\
\hline Age & .021 & & & \\
\hline UCLA-GA Medical care & & & & \\
\hline Constant & & .049 & to .010 & \\
\hline Age & & .089 & & \\
\hline Professional year & & .037 & -.091 to .142 & \\
\hline Working as a family physician & & .099 to .120 & \\
\hline
\end{tabular}

Cl: confidence interval

presented in the table because the strength of the model with age variable is higher.

\section{DISCUSSION}

Doctors who have different demographic and professional background features have different attitudes towards the elderly (7). Attitudes towards the elderly among healthcare professionals are often neutral or positive $(5,8,14)$. From this perspective, the cohort of this study, which evaluates the attitudes of family physicians actively working in elderly primary care services, shows a relatively positive attitude towards the elderly, since the mean score of UCLA-GA for all participants was 2.98 and $54.4 \%$ of the participants scored over the average, considering a score of 3 points per question as neutral in the attitude 
towards the elderly. In two studies conducted in medical students in the UK and medical students, internal medicine residents and geriatric medicine fellows in the USA, the UCLA-GA average score was found to be 3.69 and 3.90 , respectively $(15,16)$.

A more positive attitude towards the elderly was found among female family physicians. Significantly better attitude of female gender in both UCLA-GA total score and social subdimension is supported by the literature $(5,17)$. A study on ageism in a hospital in Australia found that women over 30 had more positive attitudes towards the elderly (5). Moreover, more positive attitudes of female students have been demonstrated in studies conducted in different departments such as Medicine, and Nursing $(3,13)$. However, there are studies that do not show a significant relationship between gender and attitude towards the elderly $(12,18)$.

In terms of effective and sustainable primary care, addressing attitudes towards the elderly among healthcare professionals is important (19). The effects of age, education level and working experience, together with gender, on attitude towards the elderly, were evaluated the most (20). In our study, it is seen that those who are $\geq 40$ years of age, those with professional experience $\geq 15$ years and those who work in the family medicine system $\geq 6$ years have a significantly more positive attitude towards the elderly in the medical care sub-dimension. The study in Australia found that physicians with more than 10 years of professional experience and holding a senior position display more positive attitudes towards the elderly. Additionally, it was stated that the education level, working experience and knowledge about ageing affect their attitudes towards the elderly $(1,5)$. These data coincide with the increase in chronological age and a more positive attitude in the medical care sub-dimension.

Recently, there have been studies that reveal the attitudes of young healthcare providers and students in particular. According to the results of the research that examined the change between the education process and attitudes of physiotherapy students conducted by Hobbs et al., the attitude towards the elderly increased positively during the education period (21). In another study comprising medical students, it was shown that the attitudes of medical students are related to the knowledge and experience of the students, and education and training on this subject is very important in increasing the positive attitude (22). We also found that family physicians who are $<40$ years old have more positive attitudes in the UCLA-GA social sub-dimension. In a survey conducted in recent years among younger family physicians in Turkey, physicians and family medicine residents who are $\leq 30$ years old were significantly found to have more positive attitude towards ageing (23).

Previous researches have shown that knowledge about aging is an important factor affecting attitudes towards the elderly $(8,9)$. In fact, Lee and colleagues believed that personal life supports positive attitudes toward aging and that interaction with healthy elderly in geriatric rotations removes the pre-existing negative attitudes of doctors towards aging (24). It is recommended that a positive development of the attitude towards the elderly should be focused on preuniversity education through a proactive method (25). In a recent study involving medical students in Australia, the following are forefront titles for improving attitudes towards the elderly: 1) working in research on ageing, 2) participation in didactic on successful ageing, 3) role modelling of mentors and programme staff who are closely interested in geriatrics, 4) geriatric clinical experience offering some personal exposures to older adults and 5) implementation of programmes by a centre focusing on healthy ageing. In addition, this study has revealed the efficiency of interventions with empathetic component in changing the attitudes towards the elderly, such as a recent review of interventions leading to a positive attitude change 
among doctors and medical students towards older adults, mentoring, informal contact with older adults or an ageing simulation game (19).

This paper also has some limitations. The most important limitation is related to the sample group because it covers only the family physicians who have responded on the association's mailing lists. The return of sent e-mails can also be considered somewhat low; however, this may be due to workload and the lack of interest among doctors. Another limitation can be evaluated as the weak causal aspect in the study, which, in fact, can be evaluated in connection with the purpose of the study, because determinants on the dependent variable were kept to a limited number (age, study, education, etc.). Also, according to the multivariate analysis results, gender is the only variable that affects the UCLA total score, is among the determinants of the UCLA social subdimension and the percentage of explanation is $0.015 \%$. The high autocorrelations of the three variables affecting the UCLA medical subfield score disrupted the multivariate model, and a more positive attitude in terms of medical care with increasing professional experience and age was observed in this study. On the other hand, it

\section{REFERENCES}

1. Usta $Y Y$, Demir $Y$, Yönder $M$, Yildiz A. Nursing students' attitudes toward ageism in Turkey. Arch Gerontol Geriatr 2012;54(1):90-3. (PMID: 21353316)

2. Bakirhan S, Ozkeskin M, Reyhanioglu Da, Gulpinar D. Analysis of The Attitudes and Approaches of the Physiotherapy and Rehabilitation Students Towards the Elderly. Turkish Journal of Geriatrics 2017;20(2):125-134.

3. Turgay AS, Sahin S, Aykar FS, SariD, Badir A, Ozer C. Attitudes of Turkish nursing students toward elderly people. European Geriatric Medicine 2015;6(3):267270.

4. Wood K, Gibson F, Radley A, Williams B. Pharmaceutical care of older people: what do older people want from community pharmacy? Int J Pharm Pract 2015;23(2):121-30. (PMID: 24905628) is noteworthy that young family physicians have a more positive attitude for social dimension towards the elderly.

Consequently, considering the recent international studies, a wide range of systematic (education, field application, mentorship, use of artificial intelligence, e-learning, etc.) and detailed studies are needed to determine the needs of this increasing population. Thus, plans on improving the attitudes of family physicians from communication skills to practical applications can be suggested. This planning should be made not only for the sake of the sick elderly but also for the healthy elderly, because it should be remembered that each day in the primary care, different demands and requirements may be met in the medical field related to the healthy elderly.

\section{ACKNOWLEDGEMENTS}

The study was carried out with the important contributions of family medicine associations. Therefore, the authors would like to thank the local family physician associations and all the health personnel who participated in this study.

5. Leung S, Logiudice D, Schwarz J, Brand C. Hospital doctors' attitudes towards older people. Intern Med J. 2011;41(4):308-14. (PMID: 20002850)

6. Williams D, Bennett K, Freely J. Evidence for an age and gender bias in the secondary prevention of ischemic heart disease in primary care. $\mathrm{Br} \mathrm{J}$ Clin Pharmacol. 2003;55(6);604-608. (PMID: 12814456)

7. Gunderson A, Tomkowiak J, Menachemi N, Brooks R. Rural physicians' attitudes toward the elderly: evidence of ageism? @ Manage Health Care 2005;14(3):167-76. (PMID: 16027595)

8. Lui NL, Wong CH. Junior Doctors' Attitudes Towards Older Adults and its Correlates in a Tertiary-care Public Hospital. Ann Acad Med Singapore 2009;38(2):125-9. (PMID: 19271039) 
9. Meisner BA. Physicians' attitudes toward aging, the aged, and the provision of geriatric care: a systematic narrative review. Critical Public Health 2012;22(1):6172.

10. Beecham L. Age concern survey shows ageism in NHS (Medicopolitical digest). $\mathrm{Br}$ Med J 2000; 320(7247):1479. https://doi.org/10.1136/ bmj.320.7247.1479

11. Helton MR, Pathman DE. Caring for older patients: current attitudes and future plans of family medicine residents. Fam Med 2008;40(10):707-14. (PMID: 18979258)

12. Michielutte, R, Diseker, RA. Health care providers' perceptions of the elderly and level of interest in geriatrics as a specialty. Gerontol Geriatr Educ. 19841985;5(2):65-85. (PMID: 6537370)

13. Sahin S, Mandiracioglu A, Tekin N, Senuzun F, Akcicek F. Attitudes toward the elderly among the health care providers: Reliability and validity of Turkish version of the UCLA Geriatrics Attitudes (UCLA-GA) scale. Arch Gerontol Geriatr. 2012 Jul-Aug;55(1):205-9. (PMID: 21937128)

14. Doherty M, Mitchell EA, O'Neill S. Attitudes of healthcare workers towards older people in a rural population: A survey using the Kogan Scale. Nurs Res Pract. 2011;2011:352627. (PMID: 21994823)

15. Hughes NJ, Soiza RL, Chua M, et al. Medical student attitudes toward older people and willingness to consider a career in geriatric medicine. J Am Geriatr Soc 2008;56(2):334-8. (PMID: 18179490)

16. Kishimoto $M$, Nagoshi $M$, Williams $S$, Masaki $\mathrm{KH}$, Blanchette PL. Knowledge and attitudes about geriatrics of medical students, internal medicine residents, and geriatric medicine fellows. J Am Geriatr Soc 2005;53(1):99-102. (PMID: 15667384)

17. Ozer ZC, Terkes N. Evaluation of Nursing Student's Attitudes Towards Ageism in Turkey. Procedia-Social and Behavioral Sciences 2014;116:2512-2515

18. Kalayci I, Yazıcı SO, Ozkul M, Helvaci G. Attitudes of Medical Staff And Students Towards The Elderly: Systematic Review. Adnan Menderes University Journal of Faculty of Health Sciences 2018;2(1):21-30. In Turkish

19. Wilson MA, Kurrle SE, Wilson I. Understanding Australian medical student attitudes towards older people. Australas J Ageing. 2018 Jun;37(2):93-98. (PMID: 29333700)

20. Kalaycı I, Ozkul M, Ozbek Yazıcı S, Kupeli A. The Unseen Side of Neglect And Abuse: The Importance of Assistant Personnel Education in Health Services As A Precaution Against Elder Abuse And Neglect. The Journal of Social Science 2017;4(11):576-593. In Turkish

21. Hobbs C, Dean CM, Higgs J, Adamson B. Physiotherapy students' attitudes towards and knowledge of older people. Aust J Physiother 2006;52(2):115-9. (PMID: 16764548)

22. Cankurtaran $M$, Halil M, Ulger $Z$, et al. Influence of medical education on students' attitudes towards the elderly. J Natl Med Assoc 2006;98(9):1518-22. (PMID: 17019923)

23. Caliskan T, Kendir C, Tekin N, Kartal M. Attitudes toward the elderly among young family physicians in Turkey. J Family Med Prim Care 2018;7(5):998-1001. (PMID: 30598946)

24. Lee M, Reuben DB, Ferrell BA. Multidimensional attitudes of medical residents and geriatrics fellows toward older people. J Am Geriatr Soc 2005;53 (3): 489-494. (PMID: 15743295)

25. Fitzgerald JT, Wray LA, Halter JB, Williams BC, Supiano MA. Relating medical students' knowledge, attitudes, and experience to an interest in geriatric medicine. Gerontologist 2003;43(6):849-55. (PMID: 14704384) 